\title{
ИНДИКАТОРЫ ЯДЕРНОГО ТЕХНОГЕНЕЗА НА ПРИМЕРЕ ТЕРРИТОРИИ, ПРИЛЕГАЮЩЕЙ К БЫВШЕМУ СЕМИПАЛАТИНСКОМУ ИСПЫТАТЕЛЬНОМУ ПОЛИГОНУ
}

\section{Джамбаев Мерей Тлеуканович',}

merei-semei@mail.ru

\author{
Барановская Наталья Владимировна', \\ natalya.baranovs@mail.ru
}

Липихина Александра Викторовна², a.v.lipikhina@mail.ru

\section{Боев Владислав Викторович',} v.-3@mail.ru

\section{Райымкулова Мадина Кумарбеккызы²,} madina rk@bk.ru

\author{
Апсаликова Зухра Сансызбаевназ, \\ zingatinovazs@mail.ru

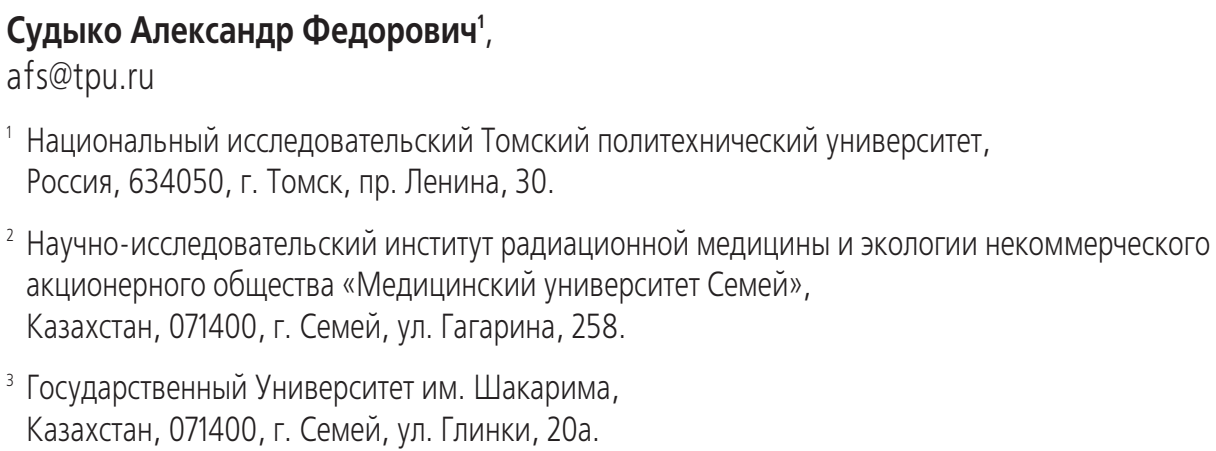

Актуальность исследования определяется необходимостью выявления индикаторных свойств химического состава компонентов природной среды, локальных и региональных особенностей их состава с учетом природных и антропогенных факторов воздействия в целях проведения экологической оценки и районирования на территориях, испытывающих специфическое воздействие объектов ядерного техногенеза. Экологическое районирование исследуемых территорий ранее проводилось только с учетом дозовых нагрузок населения, полученного в результате деятельности бывшего Семипалатинского испытательного полигона. В этой связи необходимо изучение природной геохимической специфики, что позволило бы более точно подходить к вопросу экологической оценки изучаемых территорий с учетом комплексного воздействия природных и техногенных факторов.

Цель: комплексное изучение элементного состава компонентов природной среды на территории, прилегающей к бывшему Семипалатинскому испытательному полигону.

Объекты: компоненты природной среды (почва, солевые отложения питьевой воды, продукты питания, биологические объекты). Методы. Комплекс компонентов природной среды отбирался в жилых дворах - максимально сближено во времени и пространстве. Главным критерием при выборе исследуемых жилых дворов был факт проживания респондентов в них не менее 10 лет. После соответствующей подготовки образцы отобранных компонентов исследовались с помощью инструментального нейтронно-активационного анализа.

Результаты. Показаны результаты комплексного изучения элементного состава компонентов природной среды (почва, солевые отложения питьевой воды), биологических объектов и продуктов питания на территориях, испытывающих воздействие бывшего Семипалатинского испытательного полигона. В исследуемых компонентах природной среды установлены элементы-индикаторы воздействия ядерного техногенеза, а также региональная специфика химического состава природной среды исследуемой территории в целом, проявляющаяся в накоплении U и Zn.

\footnotetext{
Ключевые слова:

Накопление химических элементов, геохимические ряды накопления, коэффициенты концентрации, компоненты природной среды, индикаторы ядерного техногенеза.
}

\section{Введение}

За период функционирования с 1949 по 1991 гг. Семипалатинский испытательный полигон (СИП) оказал мощное техногенное влияние на окружающую среду путём радиоактивного загряз- нения прилегающих территорий долгоживущими радионуклидами, тяжёлыми металлами, нарушения естественных геохимических циклов миграции химических элементов в природной среде, а также путем изменения геологической среды, раз- 
рушения и преобразования рельефа. Радиационное загрязнение окружающей среды - ключевой фактор техногенного воздействия деятельности бывшего СИП, которое носит «хронический» характер. В связи с этим становится необходимым проведение мониторинговых исследований. При этом важными аспектами радиоэкологической оценки являются ранжирование территории по уровню загрязнения, выявление путей миграции загрязняющих компонентов в природных системах. На сегодняшний день прошло около 30 лет со дня закрытия СИП. С учетом естественных процессов миграции и распада радионуклидов становится актуальной задача выявления индикаторов, достоверно указывающих на радиационное воздействие по следовым показателям. Следует учитывать, что радиационное загрязнение прилегающей территории при ядерных испытаниях является неоднородным, что создает необходимость создания линейной сетки опробования в разном направлении от источника.

Современные исследования, проведенные как непосредственно на самом полигоне, так и на территории вокруг него, направлены на изучение механизмов миграции, накопления элементов и их изотопов в отдельных средах, а также других отдаленных поствзрывных эффектов ядерных и других испытаний. Так, изучены формы нахождения трития в почвах испытательного участка «Балапан» Семипалатинского полигона [1]. Установлено, что ${ }^{137} \mathrm{Cs},{ }^{90} \mathrm{Sr},{ }^{241} \mathrm{Am},{ }^{239+240} \mathrm{Pu}$ могут генерироваться как в грубых, так и в мельчайших фракциях почвы [2]. Рассчитаны коэффициенты переноса радионуклидов ${ }^{137} \mathrm{Cs},{ }^{90} \mathrm{Sr},{ }^{241} \mathrm{Am},{ }^{239+240} \mathrm{Pu}$ в системе почва - растительный покров [3]. Результаты исследований открытых водных объектов, расположенных на территории СИП, показали, что радиоактивное загрязнение некоторых поверхностных водных объектов происходило в результате вымывания загрязнённой почвы местности, на которых она образовалась [4]. Последние исследования показали, что интенсивность миграции радионуклидов в поверхностных водах определяется их формами нахождения. Так, показано, что ${ }^{137} \mathrm{Cs}$ в воде мигрирует в коллоидной и растворенной формах, ${ }^{90} \mathrm{Sr}$ - преимущественно в растворенной форме. Фракционирование ${ }^{239+240} \mathrm{Pu}$ характерно для каждого исследованного водоема на территории СИП [5]. Согласно результатам последних исследований, подземные ядерные испытания могут стать причиной землетрясений, которые периодически продолжаются после проведенных испытаний [6]. Отмечено, что изменения геологической среды также несут потенциальную опасность негативного воздействия на окружающую среду путем активации геофизических процессов, сопровождающихся выделением токсичных и горючих газов. Так, на участках расположения эпицентров подземных ядерных испытаний наблюдаются аномальные температуры подземных вод, что может отражать воздействие геодинамических и природно-техно- генных процессов, вызванных подземными ядерными испытаниями [7].

Одной из главных задач является радиоэкологическая оценка территории, прилегающей к СИП. Так, проведен комплексный радиоэкологический мониторинг территорий, расположенных вблизи СИП, где объектами исследования являлись: почва, растения и продукты питания местного производства. В данных компонентах оценены удельные активности радионуклидов, таких как ${ }^{241} \mathrm{Am},{ }^{137} \mathrm{Cs}$ и ${ }^{239 / 240} \mathrm{Pu}[8,9]$. Также оценены активности ${ }^{137} \mathrm{Cs}$ в почве, воде, растительности и коровьем молоке в 10 точках трех регионов (Абай, Аягуз и Урджар) которые расположены к юго-востоку от СИП [10]. Показано, что содержание техногенных радионуклидов в продуктах сельскохозяйственного производства на территории, прилегающей к СИП, варьируют в пределах $n \cdot 10^{-2}-n \cdot 10^{\circ} \mathrm{Б \kappa} / \kappa г$, а в почве не превышают уровней глобальных выпадений [11].

В последнее время наряду с объектами окружающей среды в качестве индикаторов радиоактивного воздействия изучаются и биосубстраты человека. Так, в качестве индикаторов радиоактивного воздействия, связанного с профессиональной деятельностью, применяются ногти и волосы человека [12]. В ранее проведенных нами исследованиях было показано, что одним из источников поступления урана в кровь жителей населенных пунктов, расположенных на территориях, прилегающих к СИП, является питьевая вода и отмечена целесообразность детального изучения биогеохимических условий миграции урана в системе окружающая среда - организм человека [13].

Одним из важных аспектов изучения последствий ядерных испытаний, проведенных на Семипалатинском испытательном полигоне, является его отдалённые эффекты на здоровье населения, проживающего на прилегающей территории [14]. Отмечается, что несмотря на то, что современная радиоэкологическая обстановка территорий Алтайского края, которые также были подвержены радиационному загрязнению в результате деятельности СИП, не имеет ограничений для проживания и хозяйственной деятельности, к 2017 г. уровень общей заболеваемости местного населения значительно вырос [15]. Детальные результаты последних исследований различных аспектов радиационного загрязнения территории, прилегающей к бывшему СИП, приведены в работах Л.П. Рихванова, Н.В. Барановской, Т.Жћ. Мулдагалиева, А.В. Липихиной, А.В. Аклеева, В.Ф. Степаненко, M. Hoshi, M. Yamamoto, N.Y. Mudie, N. Kawano [16-22 и др.].

Таким образом, результаты многочисленных работ показывают, что геохимическая обстановка территории, прилегающей к СИП, характеризуется высокой неоднородностью. Население, проживающее на данной территории, активно использует земельные ресурсы в целях ведения личного подсобного хозяйства. Отмечены поступления некоторых химических компонентов в организм человека. Все эти факты говорят о необходимости 
комплексного подхода для установления закономерности миграции химических элементов и выявления элементов индикаторов влияния СИП.

\section{Материалы и методы}

Материалами для исследования послужили пробы объектов окружающей среды, такие как почва, полынь холодная (Artemisia frigida), солевые отложения питьевой воды, мышечной ткани крупнорогатого скота, молока, а также биосубстратов человека, таких как волосы и кровь. Объектами исследования были выбраны населенные пункты Бодене, Долонь, Канонерка, Новопокровка, Зенковка, Саржал, Медеу, Караул и Кокпекты (фоновая территория) Восточно-Казахстанской области Республики Казахстан. Данные территории отнесены к разным зонам радиационного риска, которые установлены в соответствии с законодательством Республики Казахстан (рис. 1) [23].

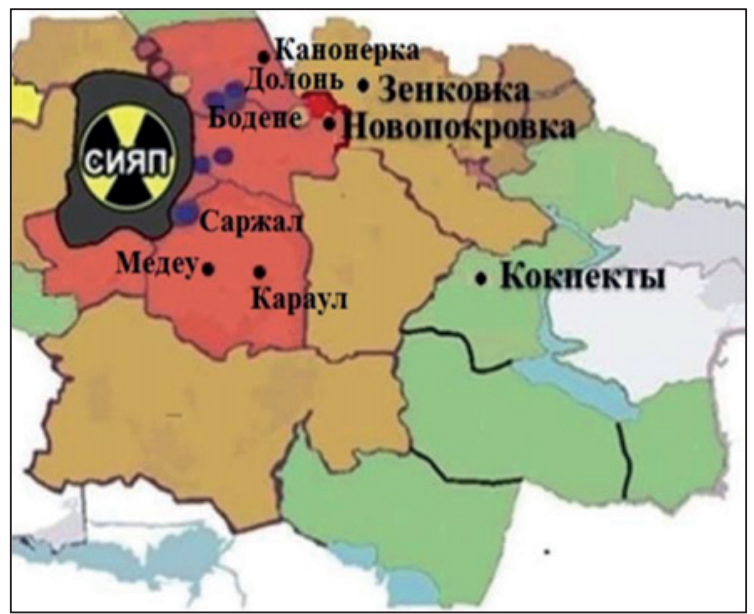

Примечание: синим иветом отлечена чрезвычайная зона, крас ным - максимальная зона, коричневым - повышенная зона радиационного риска, зеленыл - минимальная зона радиационного рис$\kappa а$, желтылм - территория с льготныл социально эконолическим статусом [23], - опробованные населенные пункты

Note: blue marked the zone of extraordinary radiation risk, red mar ked the zone of maximum radiation risk, brown noted the exceeding zone of radiation risk, green noted the minimum zone of radiation risk, yellow marked the territory with the preferential social and economic status [23],・-localities where samples were taken

Puc. 1. Обзорная карта отбора проб в населенных пунктах, расположенных на территориях, прилегающих к бывщему Семипалатинскому испытательному полигону

Fig. 1. Overview map of sampling in settlements located in the territories adjacent to the former Semipalatinsk test site

В каждом исследуемом населенном пункте комплексному пробоотбору подверглись 10 дворов. В каждом дворе отбирали по возможности весь комплекс исследуемых компонентов. Одним из важных критериев при выборе исследуемых дворов, был факт проживания респондентов на рассматриваемой территории не менее 10 лет. В итоге было отобрано 53 пробы почвы, 16 проб мышечной ткани крупнорогатого скота, 25 - коровьего молока, 27 - солевых отложений, 26 - растений (полынь холодная), 60 проб крови человека и 50 проб волос человека. Уровень накопления химических элементов определен методом инструментального нейтронно-активационного анализа (ИНАА) в ядерно-геохимической лаборатории, на базе исследовательского ядерного реактора Национального исследовательского Томского политехнического университета (аналитик с.н.с. А.Ф. Судыко). В целях проведения сравнительного анализа элементного состава почв использованы данные по условному фону, полученные на территории Тюменского федерального заказника в 2017-2018 гг. Отбор и подготовка проб осуществлена с применением стандартных методических рекомендаций. Пробу почвы отбирали методом конверта до глубины 0,05 м. Первичная масса пробы составляла 500-600 г. Пробу помещали в бумажный пакет. При пробоподготовке почва была просеяна через 2 мм сито и измельчена с применением виброистирателя. Солевые отложения отбирали из бытовой нагревательной посуды путем постукивания или ножом. Пробы крови и волос отобраны с согласия респондентов. Все пробы, за исключением почвы, помещалась в герметично закрывающийся полиэтиленовый пакет, а кровь и молоко - в вакуумные пробирки и стеклянные герметичные сосуды, соответственно. Первичная масса отобранных проб исследуемых компонентов, за исключением почвы, варьирует в пределах 10-50 г (10 и 50 мл крови и молока, соответственно). Все пробы, за исключением почвы и волос, подвергали высушиванию в муфельной печи при соответствующих температурах, до сухого состояния, и озолению мышечной ткани животных и полыни до состояния золы. После высушивания (озоления) все пробы, за исключением волос, истирали в агатовой ступке и пакетировали в алюминиевую фольгу размером $3,5 \times 3,5$ см, предварительно обработанной этиловым спиртом. Методика подготовки проб волос включала процедуры промывания от внешних загрязнителей и измельчения. Проба промывалась попеременно в ацетоне (50 мл) и дистиллированной воде (50 мл) два раза по две минуты. Высушивание пробы происходило при комнатной температуре в течение не менее 20 часов. Пробу измельчали до длины фрагментов $2-5$ мм и упаковывали в алюминиевую фольгу размером $3,5 \times 3,5$ cм.

\section{Результаты исследования и обсуждение}

С помощью инструментального нейтронно-активационного анализа в составе почвы были определены содержания таких химических элементов, как: $\mathrm{Na}, \mathrm{Ca}, \mathrm{Sc}, \mathrm{Cr}, \mathrm{Fe}, \mathrm{Co}, \mathrm{Zn}, \mathrm{As}, \mathrm{Br}, \mathrm{Rb}, \mathrm{Sr}, \mathrm{Ag}$, $\mathrm{Sb}, \mathrm{Cs}, \mathrm{Ba}, \mathrm{La}, \mathrm{Ce}, \mathrm{Nd}$, Sm, Eu, Tb, Yb, Lu, Hf, Ta, $\mathrm{Au}, \mathrm{Th}, \mathrm{U}$. По результатам анализа проведен расчет статистических параметров содержания химических элементов в почвах изученной территории. Рассчитаны такие показатели, как: среднее арифметическое значение $(m)$, геометрическое среднее $(G)$, медиана $\left(X_{\text {med }}\right)$, стандартная ошибка среднего 
$(\sigma)$, стандартное отклонение $(S)$, коэффициент вариации $\left(K_{\mathrm{s}}\right)$, минимальное значение $(\mathrm{min})$ и максимальное значение (max) (табл. 1). Видно, что содержание химических элементов в составе почвы исследуемой территории подчиняется нормальному закону распределения. Коэффициенты вариации таких элементов, как: $\mathrm{Ca}, \mathrm{Br}, \mathrm{Rb}, \mathrm{Sr}, \mathrm{Sb}, \mathrm{Cs}, \mathrm{Nd}$, $\mathrm{Eu}, \mathrm{Tb}, \mathrm{Ta}, \mathrm{Au}$, варьируют в диапазоне от 50 до $100 \%$, что соотвествует высокой неоднородности их распределения. Концентрации $\mathrm{Ag}$ были ниже пределов обнаружения во всех пробах.

На рис. 2 приведена диаграмма сравнения элементного состава почвы исследуемой территории с почвой Томской области (Т0), как территории со схожей техногенной нагрузкой, определенной воздействием ядерного техногенеза, а также с почвой Тюменского федерального заказника (ТФЗ), установленной нами как условно фоновая [24].

Видно, что элементный состав почв территории, прилегающей к СИП и Томской области имеют схожую специфику, которая проявляется в более высоком содержании всех элементов, за исключением $\mathrm{Au}$, по сравнению с территорией Тюменского федерального заказника. Учитывая тот факт, что типы почв, определяемые природными условиями Томской области и Восточно-Казахстанской области, на которой расположен СИП, отличаются, можно предположить, что специфика их элементного состава определяется воздействием одинакового техногенного фактора. Кроме того, очень низкие концентрации практически всех химических элементов в составе почвы Тюменского федерального заказника характеризует территорию как не загрязненную, что позволяет рассматривать ее в дальнейшем как фоновую территорию. Анализ нормированных показателей относительно кларковых содержаний химических элементов по А.А. Ярошевскому [25] подтверждает вывод о наличии схожей картины накопления химических элементов на территориях воздействия ядерного техногенеза (Предприятие ядерно-топливного цикла Сибирского химического комбината в Томской области и Территория СИП) (рис. 3). таблииа 1. Статистические показатели химических элементов в почвах территории, прилегающей к бывшему Семипалатинскому испытательному полигону $(N=53)$

Table 1. Statistical indicators of chemical elements in soils of the territory adjacent to the former Semipalatinsk test site $(N=53)$

\begin{tabular}{|c|c|c|c|c|c|c|c|c|}
\hline & $m$ & $\sigma$ & $G$ & $X_{\text {med }}$ & $S$ & $\min$ & $\max$ & $K_{\text {в }}$ \\
\hline $\mathrm{Na}$ & 15549 & 352 & 2560 & 15100 & 2560 & 9900 & 23083 & 16 \\
\hline $\mathrm{Ca}$ & 20686 & 1514 & 11020 & 18100 & 11020 & 1200 & 52800 & 53 \\
\hline $\mathrm{Sc}$ & 10,8 & 0,5 & 3,4 & 11,1 & 3,4 & 4,4 & 19,6 & 31 \\
\hline $\mathrm{Cr}$ & 75,4 & 2,9 & 21 & 81,0 & 21,4 & 7,0 & 106 & 28 \\
\hline $\mathrm{Fe}$ & 31104 & 1216 & 8856 & 31400 & 8856 & 13955 & 54858 & 28 \\
\hline $\mathrm{Co}$ & 12,0 & 0,8 & 5,7 & 12,7 & 5,7 & 0,1 & 25,2 & 48 \\
\hline $\mathrm{Zn}$ & 205 & 12,4 & 90 & 210 & 90,1 & 52,3 & 391 & 44 \\
\hline $\mathrm{As}$ & 5,7 & 0,3 & 2 & 5,6 & 2,5 & 1,4 & 11,1 & 43 \\
\hline $\mathrm{Br}$ & 12,8 & 1,2 & 8,8 & 145 & 8,8 & 0,5 & 42,4 & 69 \\
\hline $\mathrm{Rb}$ & 67,4 & 5,1 & 37 & 70,4 & 37,3 & 2,5 & 193 & 55 \\
\hline $\mathrm{Sr}$ & 175 & 17,7 & 132 & 145 & 129 & 60,0 & 510 & 73,8 \\
\hline $\mathrm{Ag}$ & $<1$ & - & - & - & - & - & - & - \\
\hline $\mathrm{Sb}$ & 1,0 & 0,1 & 1,0 & 70,4 & 1,0 & 0,03 & 5,0 & 93 \\
\hline $\mathrm{Cs}$ & 2,8 & 0,2 & 1,4 & 0,9 & 1,4 & 0,1 & 4,5 & 51 \\
\hline $\mathrm{Ba}$ & 437 & 15,5 & 113 & 3,3 & 113 & 27,4 & 684 & 26 \\
\hline $\mathrm{La}$ & 22,9 & 0,7 & 5,0 & 450 & 5,0 & 8,6 & 31,2 & 22 \\
\hline $\mathrm{Ce}$ & 49,9 & 2,0 & 14,2 & 22,6 & 14,2 & 1,5 & 68,9 & 29 \\
\hline $\mathrm{Nd}$ & 16,2 & 1,5 & 11,0 & 51,6 & 11,0 & 0,5 & 49,5 & 68 \\
\hline $\mathrm{Sm}$ & 4,5 & 0,2 & 1,1 & 19,9 & 1,1 & 2,3 & 7,8 & 25 \\
\hline $\mathrm{Eu}$ & 0,9 & 0,1 & 0,5 & 4,4 & 0,5 & 0,01 & 2,2 & 55 \\
\hline $\mathrm{Tb}$ & 0,6 & 0,05 & 0,4 & 1,1 & 0,4 & 0,03 & 1,3 & 64 \\
\hline $\mathrm{Yb}$ & 2,5 & 0,08 & 0,6 & 0,7 & 0,6 & 0,8 & 3,5 & 24 \\
\hline $\mathrm{Lu}$ & 0,4 & 0,01 & 0,1 & 2,4 & 0,1 & 0,2 & 0,5 & 22 \\
\hline $\mathrm{Hf}$ & 5,2 & 0,2 & 1,6 & 0,4 & 1,6 & 2,1 & 8,0 & 31 \\
\hline $\mathrm{Ta}$ & 0,7 & 0,07 & 0,5 & 4,9 & 0,5 & 0,01 & 2,6 & 80 \\
\hline $\mathrm{Au}$ & 0,01 & 0,003 & 0,02 & 0,8 & 0,02 & 0,001 & 0,2 & 334 \\
\hline $\mathrm{Th}$ & 6,8 & 0,3 & 2,5 & 0,001 & 2,5 & 2,6 & 16,8 & 37 \\
\hline $\mathrm{U}$ & 2,6 & 0,1 & 0,7 & 6,4 & 0,7 & 0,1 & 4,2 & 28 \\
\hline
\end{tabular}

Примечание: $m$ - среднее, $\sigma$ - стандартная ошибка среднего, $G$ геометрическое среднее, $X_{\text {med }}$ - медиана, $S$ - стандартное откло-

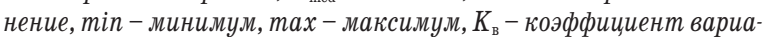
иии, <- ниже указанного предела обнаружения.

Note: $m$ is the mean, $\sigma$ is the standard error of mean, $G$ is geometric mean, $X_{\text {med }}$ is the median, $S$ is the standard deviation, min-minimum, max-maximum, $K_{\mathrm{B}}$ is the coefficient of variation, $<-$ below the stated detection limit.

Для территории, прилегающей к СИП, существует деление по степени радиационного риска.

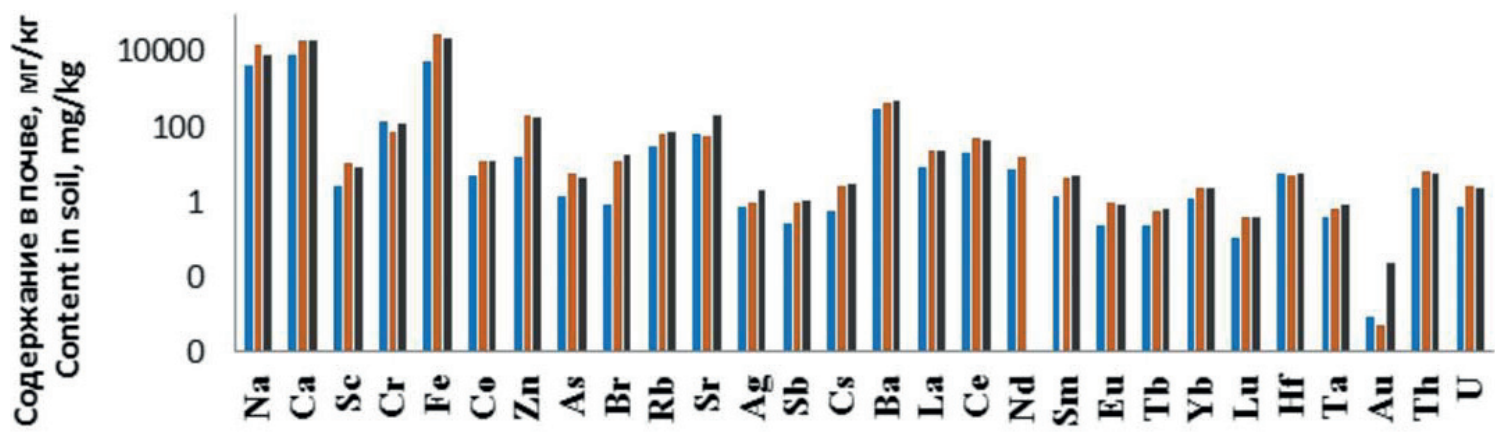

$$
\begin{aligned}
& \text { - ТФ3 }(n=20)-\text { СИП }(n=53) \square \text { Томская область }(n=192) \\
& \text { - TFR }(\mathrm{n}=20) \square \text { SNT }(\mathrm{n}=53) \square \quad \text { Tomsk region }(\mathrm{n}=192)
\end{aligned}
$$

Pис. 2. Сравнительные данные содержания хилических элелентов в почвах локальных территорий, мг/кг

Fig. 2. Comparative data of chemical elements content in soils of local territories, $\mathrm{mg} / \mathrm{kg}$ 


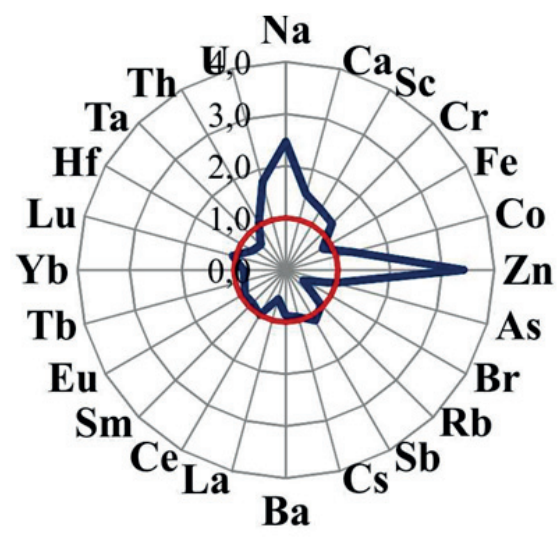

Территория, прилегающая к бывшему

Семипалатинскому испытательному полигону Territory adjacent to the former Semipalatinsk test site

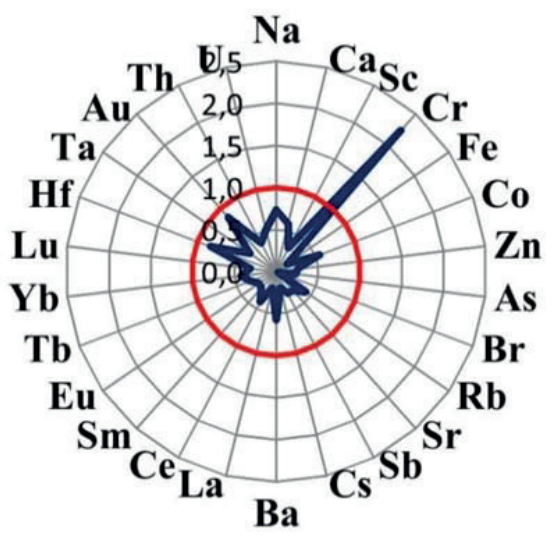

Тюменский федеральный заказник Tyumen Federal reserve

Нами рассмотрена концентрация химических элементов в почвах данных зон. На рис. 4 приведены коэффициенты концентраций химических элементов в почвах территорий, прилегающих к СИП, ранжированных по уровню радиационного риска, относительно кларка по А.А. Ярошевскому [25].

Для почвы чрезвычайной зоны радиационного риска характерно накопление $\mathrm{Na}, \mathrm{Sc}, \mathrm{Zn}$ и U (4 элемента). Для почвы максимальной зоны радиационного риска - $\mathrm{Na}, \mathrm{Ca}, \mathrm{Sc}, \mathrm{Cr}, \mathrm{Co}, \mathrm{Zn}, \mathrm{Lu}$, Th и U (9 элементов). В почве территории с повышенным уровнем радиационного риска накапливается максимальный спектр элементов, таких как $\mathrm{Na}, \mathrm{Ca}$, $\mathrm{Sc}, \mathrm{Cr}, \mathrm{Co}, \mathrm{Zn}, \mathrm{As}, \mathrm{Rb}, \mathrm{Sb}, \mathrm{Cs}, \mathrm{Ce}, \mathrm{Sm}, \mathrm{Eu}, \mathrm{Tb}, \mathrm{Lu}, \mathrm{Ta}$, Th и U (18 элементов). Специфика элементного состава почвы данной территории отражается в накоплении $\mathrm{Rb}, \mathrm{Ce}, \mathrm{Sm}, \mathrm{Tb}, \mathrm{Ta}$. Для почвы минимальной зоны радиационного риска характерно накопление $\mathrm{Na}, \mathrm{Ca}, \mathrm{Sc}, \mathrm{Cr}, \mathrm{Co}, \mathrm{Zn}, \mathrm{As}, \mathrm{Sr}, \mathrm{Sb}, \mathrm{Cs}, \mathrm{Eu}$ и U (12 элементов). Специфичным для почвы данной территории является накопление Sr. Суммарные показатели загрязнения сравниваемых территорий не соответствуют их рангам, установленным по уровню радиационного риска. Максимальный

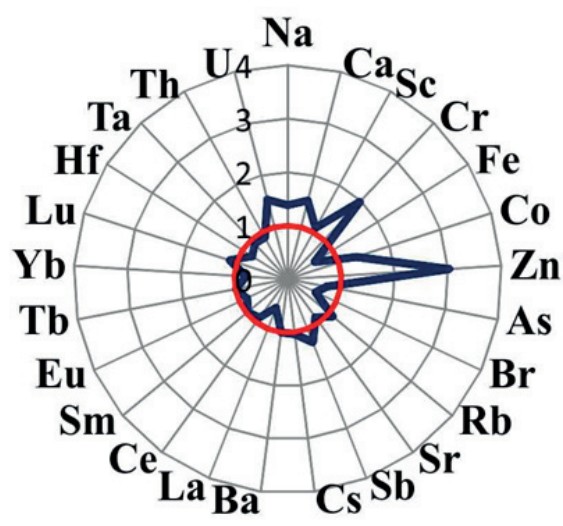

Томская область Tomsk region

Рис. 3. Коэффициенты кониентраций химических элементов в почвах территории, прилегающей к бывшему Селипалатинскому испьтательному полигону, относительно кларка по А.А. Ярошевскому [25]

Fig. 3. Coefficients of concentrations of chemical elements in soils of the territory adjacent to the former Semipalatinsk test site, relative to clark by A.A. Yaroshevsky [25]

уровень суммарных показателей загрязнения характерен для почв с повышенной и минимальной зонами радиационного риска. Элементами, одинаково значимо $(\kappa K \geq 1)$ накапливающимися во всех зонах радиационного риска, являются $\mathrm{Na}, \mathrm{Sc}, \mathrm{Zn}$ и U. Учитывая тот факт, что коэффициенты вариации $\mathrm{Na}, \mathrm{Zn}, \mathrm{Sc}$ и U ниже 50 \%, можно сделать вывод о природности специфики накопления данных химических элементов в составе почв исследуемой территории в целом. Согласно методическим рекомендациям по уровню коэффициентов вариаций $\leq 50 \%$ различают однородный характер распределения содержания химических элементов [26].

В целях выявления индикаторных компонентов, отражающих природную и техногенную геохимическую специфику исследуемой территории, изучен элементный состав комплекса различных объектов, в том числе биосубстратов человека. В табл. 2 приведены основные параметры накопления химических элементов в составе полыни холодной, молока, мышечной ткани животных, солевых отложений питьевой воды (накипи), крови и волос человека, отобранных на данной территории. 


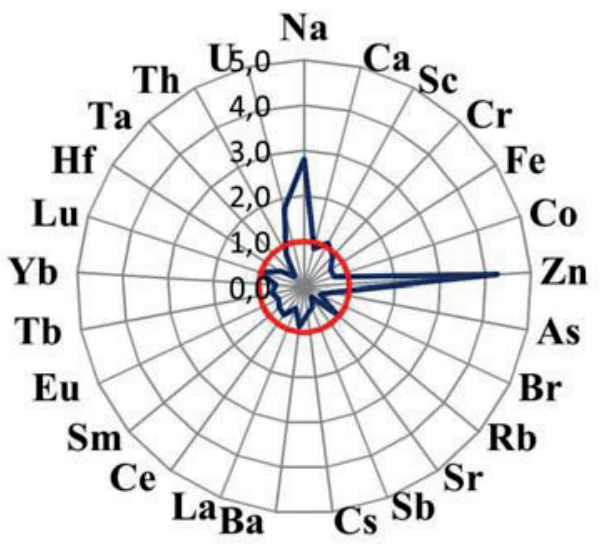

Чрезвычайная зона радиационного риска, $Z_{\mathrm{Cпз}}=6,9$ Zone of extraordinary radiation risk, $Z_{\mathrm{TPI}}=6,9$

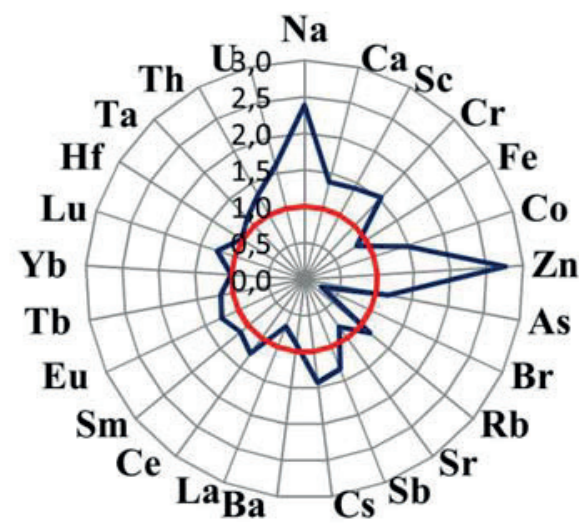

Повышенная зона радиационного риска, $Z_{\mathrm{Cпз}}=9,2$ Zone of extraordinary radiation risk, $Z_{\mathrm{TPI}}=9,2$

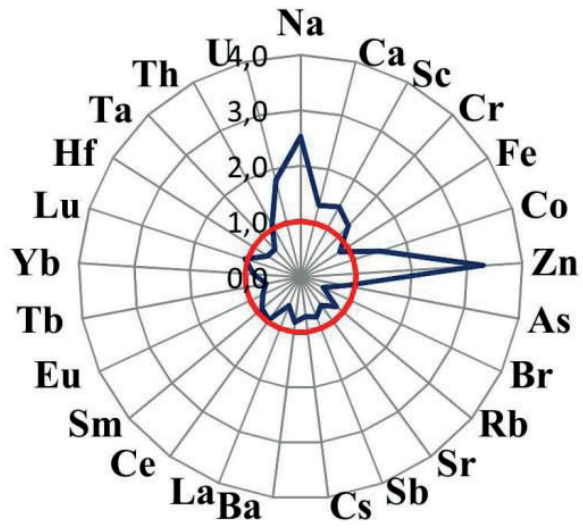

Максимальная зона радиационного риска, $Z_{\mathrm{Cп3}}=7,2$ Zone of maximum radiation risk, $Z_{\mathrm{TPI}}=7,2$

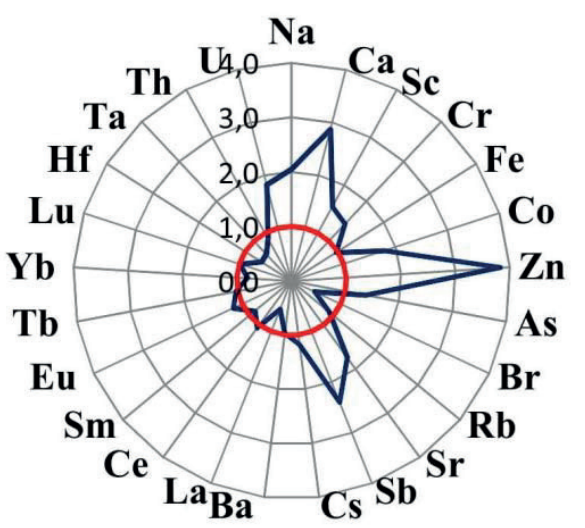

Минимальная зона радиационного риска, $Z_{\mathrm{C} п 3}=12,2$ Zone of maximum radiation risk, $Z_{\mathrm{TPI}}=12,2$

Pис. 4. Коэффициенты концентрации хилических элементов в почвах территорий, прилегающих к бывшему Семипалатинсколу ис пытательному полигону, ранжированных по уровню радиационного риска, относительно кларка по А.А. Ярошевскому [25]

Fig. 4. Coefficients of concentrations of chemical elements in soils of territories adjacent to the former Semipalatinsk test site, ranked by the radiation risk level, relative to Clark by A.A. Yaroshevsky [25]

Сравнительный анализ уровней накопления химических элементов в составе исследованных сред позволяет выявить объекты, которые выполняют функцию концентраторов, являясь возможным источником поступления определенных элементов в организм человека. Видно, что основным концентратором $\mathrm{Ca}, \mathrm{Cr}, \mathrm{Fe}, \mathrm{Co}, \mathrm{Zn}, \mathrm{As}, \mathrm{Sr}, \mathrm{Sb}$, $\mathrm{Ba}, \mathrm{Nd}, \mathrm{Lu}, \mathrm{Ta}, \mathrm{U}$ является накипь. Полынь является концентратором $\mathrm{Sc}, \mathrm{Br}, \mathrm{Rb}, \mathrm{Cs}, \mathrm{La}, \mathrm{Ce}, \mathrm{Sm}, \mathrm{Eu}$, $\mathrm{Tb}, \mathrm{Yb}, \mathrm{Hf}$ и Th. Для остальных биологических объектов характерны небольшие вариации макрокомпонентов и относительно одинаковые содержания редкоземельных элементов.

В табл. 3 приведены биогеохимические ряды накопления химических элементов в компонентах природной среды и биосубстратах человека. Коэффициенты концентраций были рассчитаны для почв территории, прилегающей к СИП, относительно кларка по А.А. Ярошевскому [25], для со- левых отложений питьевой воды относительно солевых отложений воды озера Байкал, вода которой принята как эталон чистой воды [27], для крови человека относительно данных по G.V. Iengar и др. [28], для волос человека относительно среднего на территории Павлодарской области Республики Казахстан по данным Н.П. Корогод [29], для полыни относительно состава покрытосеменных видов растений по Н.J.M. Bowen [30], для молока относительно элементного состава организма млекопитающих по H.J.M. Bowen [30], для тканей животных относительно мускульных тканей млекопитающих по H.J.M. Bowen [30]. Из таблицы видно, что общей чертой всех рассматриваемых компонентов природной среды и биосубстратов человека является накопление U. Кроме того, коэффициенты концентрации $\mathrm{Zn} \geq 1$ в составе почти всех рассматриваемых сред, за исключением молока. Суммарные показатели накопления химических эл- 
Таблица 2. Химические элементы в составе компонентов природной среды территории, прилегающей к бывщелу Семипалатинскому испытательному полигону, мг/кг

Table 2. Chemical elements in the components of the environment of the treeitory adjacent to the former Semipalatinsk test site, mg/kg

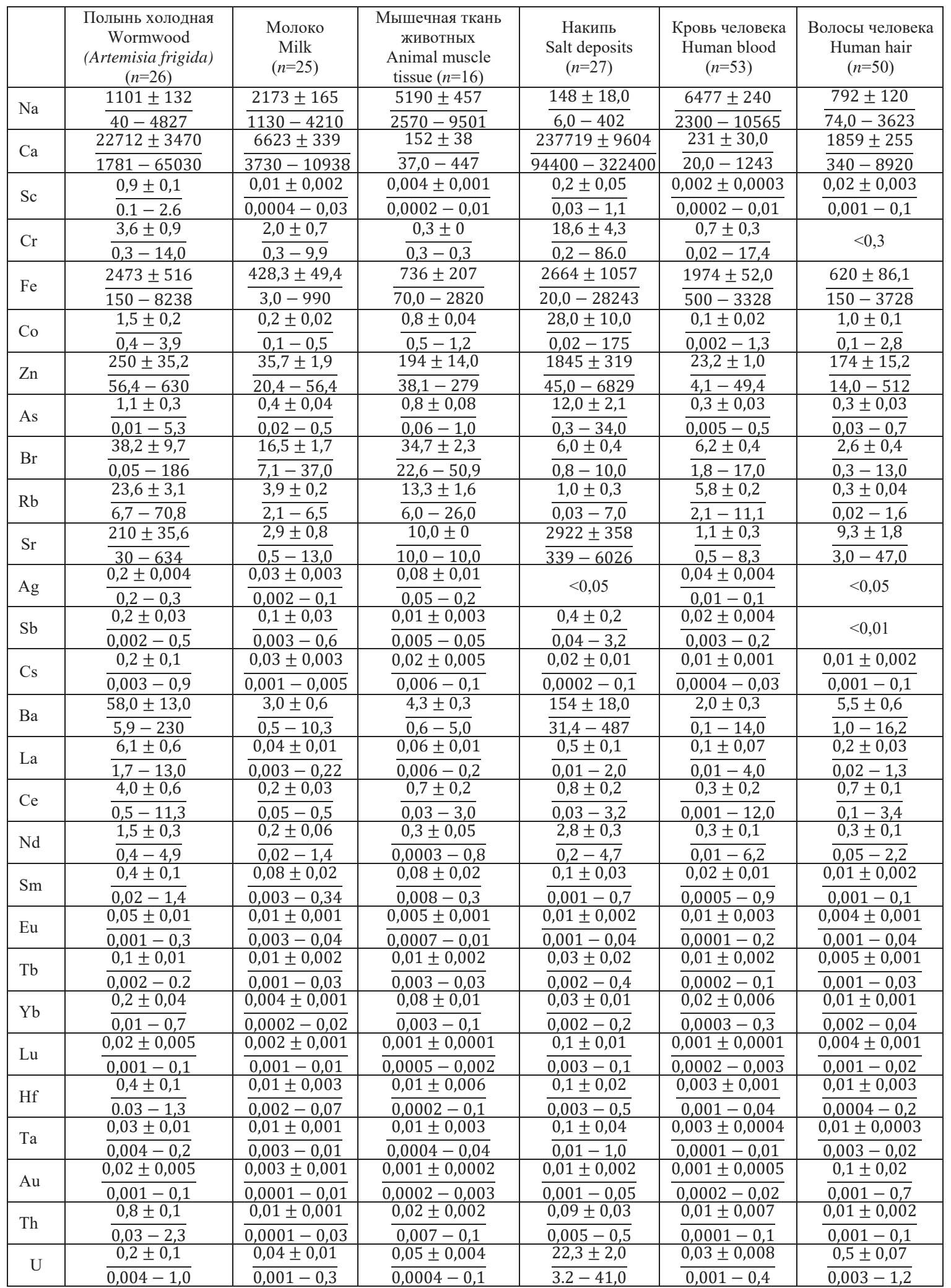

Прилечание: < - ниже указанного предела обнаружения; в числителе - среднее арифметическое содержание \pm стандартная ошибка среднего, в зналенателе - минилальное и максилальное значение.

Note: $<-$ below the specified detection limit; in the numerator - the arithmetic mean \pm the standard error of the mean, in the denominator - minimum and maximum value 
ементов, концентрируемых $\geq 1$, максимальны для полыни и накипи, что подтверждает вывод о том, что данные компоненты являются основными концентраторами химических элементов. Следующей средой, активно накапливающей химические элементы, является кровь человека. Далее следуют волосы человека и мышечная ткань животных. Для молока характерен минимальный показатель накопления, равный 24. Почва является средой, концентрирующей химические элементы в наименьшей степени. Таким образом, полученные данные свидетельствуют о том, что наиболее чувствительным компонентом, реагирующим на состояние окружающей среды накапливанием химических элементов, является живой организм.

Анализ коэффициентов концентрации элементов в изучаемых компонентах, полученных при нормировании к единому кларку, показал, что наблюдается занижение значений всех показателей, поскольку кларк является весьма специфичным для многих из изучаемых компонентов [31]. Можно отметить сохранение закономерности концентрирования цинка для всех компонентов природной среды территории, прилегающей к бывшему испытательному полигону. Уран концентрируется выше единицы в таких средах, как накипь и почва. Вероятно, невысокие показатели коэффициента концентрации для урана в биологических объектах связаны с высоким кларковым показателем, не учитывающим эти среды.

\section{Заключение}

Природная геохимическая специфика элементного состава почв территории, прилегающих $\kappa$ СИП, выражается в накоплении $\mathrm{Na}, \mathrm{Sc}, \mathrm{Zn}$ и U. Территории, расположенные наиболее удаленно от СИП, отличаются максимальной химической загруженностью. Суммарные показатели загрязнения почв территорий, ранжированных по уровням дозовых нагрузок, максимальны для почв с повышенным и минимальным уровнем радиационного риска.

\section{СПИСОК ЛИТЕРАТУРЫ}

1. Serzhanova Z.B., Aidarkhanova A.K., Lukashenko S.N., Lyakhova 0.N., Timonova L.V., Raimkanova A.M. Researching of tritium speciation in soils of «Balapan» site // Journal of environmental radioactivity. - 2018. - V. 192. - P. 621-627.

2. Kabdyrakova A.M., Lukashenko S.N., Mendubaev A.T., Kunduzbayeva A.Y., Panitskiy A.V., Larionova N.V. Distribution of artificial radionuclides in particle-size fractions of soil on fallout plumes of nuclear explosions // Journal of environmental radioactivity. - 2018. - V. 186. - P. 45-53.

3. Larionova N.V., Lukashenko S.N., Kabdyrakova A.M., Kunduzbayeva A.Y., Panitskiy A.V., Ivanova A.R. Transfer of radionuclides to plants of natural ecosystems at the semipalatinsk test site //Journal of environmental radioactivity. - 2018. - V. 186. - P. 63-70.

4. Aidarkhanova A.K., Lukashenko S.N., Larionova N.V., Polevik V.V. Radionuclide transport in the «sediments - water plants» system of the water bodies at the Semipalatinsk test site //
Таблица 3. Биогеохимические ряды накопления химических әлементов в компонентах природной среды и биосубстратов человека, проживающего на территориях, прилегающих к бывшему Семипалатинскому испытательному полигону

Table 3. Biogeochemical series of accumulation of chemical elements in the components of the natural environment and biosubstrates of a person living in the territories adjacent to the former Semipalatinsk test site

\begin{tabular}{|c|c|c|}
\hline \begin{tabular}{|c|} 
Компонент \\
прироной среды \\
Component \\
of environment
\end{tabular} & $\begin{array}{l}\text { Биогеохимические ряды } \\
\text { Biogeochemical series }\end{array}$ & $\begin{array}{c}\text { Суммарный пока- } \\
\text { затель накопления } \\
\text { Total accumula- } \\
\text { tion index }\end{array}$ \\
\hline \begin{tabular}{|l} 
Почва \\
Soil
\end{tabular} & $\begin{array}{c}\mathrm{Zn}_{3,4} \mathrm{Na}_{2,5} \mathrm{U}_{1,7} \mathrm{Ca}_{1,5} \mathrm{Sc}_{1,4} \mathrm{Co}_{1,3} \mathrm{Cr}_{1,3} \\
\mathrm{Lu}_{1,1} \mathrm{Sb}_{1,1} \mathrm{Th}_{1,0} \mathrm{Ce}_{1,0} \mathrm{Rb}_{1,0} \mathrm{As}_{1,0} \\
\mathrm{Cs}_{1,0} \mathrm{Sm}_{1,0} \mathrm{Eu}_{1,0} \mathrm{Ba}_{1,0} \mathrm{~Tb}_{1,0} \mathrm{Yb}_{1,0} \\
\mathrm{Fe}_{1,0} \mathrm{Sr}_{1,0}\end{array}$ & $\begin{array}{l}\mathrm{Z}_{\mathrm{CIH}}=6,9 \\
\mathrm{Z}_{\mathrm{TPI}}=6,9\end{array}$ \\
\hline $\begin{array}{l}\text { Накипь } \\
\text { Salt deposits }\end{array}$ & $\begin{array}{l}\mathrm{Zn}_{115} \mathrm{Ta}_{7,3} \mathrm{U}_{4,9} \mathrm{Lu}_{3,5} \mathrm{~Tb}_{3,2} \mathrm{Nd}_{2,9} \mathrm{As}_{2,8} \\
\mathrm{Cr}_{2,2} \mathrm{Fe}_{1,8} \mathrm{Sr}_{1,8} \mathrm{Co}_{1,5} \mathrm{Eu}_{1,1} \mathrm{Sb}_{1,1} \mathrm{Ca}_{1,0}\end{array}$ & $\begin{array}{l}\mathrm{Z}_{\mathrm{CIH}}=137 \\
\mathrm{Z}_{\mathrm{TPI}}=137\end{array}$ \\
\hline \begin{tabular}{|l} 
Полынь холодная \\
Wormwood \\
(Artemisia frigida)
\end{tabular} & $\begin{array}{r}\mathrm{Yb}_{211}, \mathrm{Sc}_{11,}, \mathrm{Au}_{81,} \mathrm{La}_{72,}, \mathrm{Sm}_{69}, \mathrm{~Tb}_{67}, \\
\mathrm{Fe}_{18,}, \mathrm{Cr}_{16,}, \mathrm{Sr}_{8}, \mathrm{U}_{5,6} \mathrm{As}_{5,5} \mathrm{Ba}_{4,1} \mathrm{Co}_{3,2} \\
\mathrm{Ag}_{2,6} \mathrm{Sb}_{2,6} \mathrm{Br}_{2,5} \mathrm{Eu}_{2,2} \mathrm{Zn}_{1,6}\end{array}$ & $\begin{array}{l}\mathrm{Z}_{\mathrm{CIH}}=665 \\
\mathrm{Z}_{\mathrm{TPI}}=665\end{array}$ \\
\hline \begin{tabular}{|l|} 
Mолоко \\
Milk \\
\end{tabular} & $\begin{array}{c}\mathrm{Cr}_{13,6} \mathrm{Ag}_{4,9} \mathrm{Br}_{4,1} \mathrm{Fe}_{2,7} \mathrm{U}_{2,0} \mathrm{As}_{1,8} \\
\mathrm{Ba}_{1,3} \mathrm{Sc}_{1,2}\end{array}$ & $\begin{array}{l}\mathrm{Z}_{\mathrm{CIH}}=24 \\
\mathrm{Z}_{\mathrm{TPI}}=24\end{array}$ \\
\hline $\begin{array}{l}\text { Мышечная ткань } \\
\text { животных } \\
\text { Animal muscle } \\
\text { tissue }\end{array}$ & $\begin{array}{l}\mathrm{Ag}_{13,2} \mathrm{Br}_{8,7} \mathrm{Fe}_{4,6} \mathrm{As}_{4,2} \mathrm{Co}_{2,8} \mathrm{U}_{2,2} \\
\mathrm{Ba}_{2,0} \mathrm{Cr}_{2,0} \mathrm{Ce}_{1,5} \mathrm{Zn}_{1,2} \mathrm{Rb}_{1,0} \mathrm{Na}_{1,0}\end{array}$ & $\begin{array}{l}\mathrm{Z}_{\mathrm{CIIH}}=32 \\
\mathrm{Z}_{\mathrm{TPI}}=32\end{array}$ \\
\hline \begin{tabular}{|l|} 
Кровь человека \\
Human blood \\
\end{tabular} & $\begin{array}{l}\mathrm{Sr}_{21,2} \mathrm{As}_{11,2} \mathrm{Ba}_{9,2} \mathrm{U}_{5,8} \mathrm{Fe}_{4,3} \mathrm{Na}_{3,1} \mathrm{Zn}_{3,1} \\
\mathrm{Ca}_{2,7} \mathrm{Th}_{2,3} \mathrm{Sb}_{2,2} \mathrm{Rb}_{2,2} \mathrm{Au}_{1,3} \mathrm{Br}_{1,2} \mathrm{Cs}_{1,0}\end{array}$ & $\begin{array}{l}\mathrm{Z}_{\mathrm{CIH}}=57 \\
\mathrm{Z}_{\mathrm{TPI}}=57\end{array}$ \\
\hline $\begin{array}{l}\text { Волосы человека } \\
\text { Human hair }\end{array}$ & $\begin{array}{c}\mathrm{Fe}_{14} \mathrm{Co}_{10} \mathrm{Ce}_{5} \mathrm{Sc}_{3} \mathrm{Rb}_{3} \mathrm{Na}_{2} \mathrm{La}_{2} \mathrm{U}_{2} \mathrm{Lu}_{1} \\
\mathrm{Ca}_{1} \mathrm{Ta}_{1} \mathrm{Au}_{1} \mathrm{Zn}_{1}\end{array}$ & $\begin{array}{l}\mathrm{Z}_{\mathrm{CIH}}=34 \\
\mathrm{Z}_{\mathrm{TPI}}=34\end{array}$ \\
\hline
\end{tabular}

Примечание: красным иветом выделены химические элементы, имеющие общую специфику накопления для всех рассматриваемых сред.

Note: chemical elements with common accumulation specificity in all studied media are highlighted in red.

Накипь и полынь холодная (Artemisia frigida) являются основными концентраторами химических элементов, в том числе отражающих природную геохимическую специфику территории в целом, которая выражается в накоплении $\mathrm{Zn}$ и U почти во всех исследованных компонентах. Наиболее чувствительными индикаторами, активно концентрирующими химические элементы, являются живые системы.

Journal of environmental radioactivity. - 2018. - V. 184. P. $122-126$.

5. Торопов А.С. Фракционирование форм нахождения техногенных радионуклидов в водных объектах семипалатинского испытательного полигона // Известия томского политехнического университета. инжиниринг георесурсов. - 2018. - Т. 329. № 6. - C. 74-84.

6. Triggered seismicity after north Korea's 3 September 2017 nuclear test / J. Yao, D. Tian, Z. Lu, L. Sun, L. Wen // Seismol Res Lett. - 2018. - V. 89. - № 6. - P. 2085-2093.

7. Тепловые особенности в районе «боевой» скважины 104 семипалатинского испытательного полигона / В.В. Романенко, Д.Е. Аюнов, А.Д. Дучков, С.А. Казанцев // Интерэкспо гео-сибирь. - 2017. - Т. 2. - № 4. - С. 123-128.

8. Radioecological monitoring of adjacent territories to the former Semipalatinsk nuclear test site, east Kazakhstan / S. Duyssembaev, A. Serikova, S. Suleimenov, N. Ikimbayeva, A. Zhexenaye- 
va, A. Akhemtzhanova, Z. Atambayeva // International Journal of Engineering and Technology. - 2018. - V. 7. - P. 323-328.

9. Дюсембаев С.Т., Серикова А.Т., Иминова Д.Е. Содержание америция-241 и цезия-137 в пробах окружающей среды и продуктах животноводства // Молодой ученый. - 2017. - № 6.1. C. 11-17.

10. Kakimov A., Yessimbekov Z., Kakimova Z., Bepeyeva A., Stuart M. Cs-137 in milk, vegetation, soil, and water near the former soviet Union's Semipalatinsk Nuclear Test Site //Environmental Science and Pollution Research. - 2016. - V. 23. - № . 5. P. $493-497$.

11. Кожаханов Т.Е., Лукашенко С.Н. Содержание радионуклидов ${ }^{137} \mathrm{Cs},{ }^{90} \mathrm{Sr},{ }^{239+240} \mathrm{Pu}$ и ${ }^{241} \mathrm{Am}$ в продукции растениеводства на территориях, прилегающих к Семипалатинскому испытательному полигону // Радиационная биология. Радиоэкология. 2017. - № 2. - C. 2205-2225.

12. Brown J.W.N., Brockman J.D., Robertson J.D. Measurement of ${ }^{239} \mathrm{Pu}$ in keratinous materials: A potential non-invasive bioassay for monitoring human exposure // Applied Radiation and Isotopes. -2017 . - V. 128. - P. 132-135.

13. Джамбаев М.Т., Жакупова Ш.Б., Брайт Ю.Ю. Уран в питьевой воде и крови человека в зоне влияния Семипалатинского ядерного полигона // Проблемы геологии и освоения недр: труды XX Международного симпозиума имени академика М.А. Усова студентов и молодых ученых, посвященного 120-летию со дня основания Томского политехнического университета. Томск: Изд-во Томского политехнического университета, 2016. - C. 122-124.

14. The state scientific automated medical registry, Kazakhstan: an important resource for low-dose radiation health research / K.N. Apsalikov, A. Lipikhina, B. Grosche, T. Belikhina, E. Ostroumova, S. Shinkarev, V. Stepanenko, T. Muldagaliev, S. Yoshinaga, T. Zhunussova, M. Hoshi, H. Katayama, D.T. Lackland, S.L. Simon, A. Kesminiene // Radiat Environ Biophys. 2019. - V. 58. - № 1. - P. 1-11.

15. Колядо И.Б., Плугин С.В., Трибунский С.И. Последствия влияния радиационного воздействия на территорию и население Алтайского края // Гигиена и санитария. - 2018. - Т. 97. - № 7. C. 609-617.

16. Очерки геохимии человека / Н.В. Барановская, Л.П. Рихванов, Т.Н. Игнатова, Д.В. Наркович, О.А. Денисова. - Томск: Дельтаплан, 2015. - 377 с.

17. Muldagaliev T., Apsalikov K., Belihina T. Scientific foundations of screening organization of the state of health of Kazakhstanean population subjected to radiation, analyses of the results, development prenozological preventive measures and rehabilitation // $17^{\text {th }}$ Hiroshima International Symposium. - Япония, 2012. $43 \mathrm{p}$.

18. Липихина А.В. Радиоэкологическая обстановка и оценка дозовых нагрузок от долговременного воздействия радионуклидов в районе Семипалатинского испытательного ядерного полигона: на примере Абайского района: автореф. дис.... канд. биол. наук. - Томск, 2005. - 163 с.

19. Аклеев А.В. Реакция тканей на хроническое воздействие ионизирующего излучения // Радиационная биология. Радиоэ- кология. - 2009. - № 1. - С. 5-17.

20. International intercomparison of retrospective luminescence dosimetry method: sampling and distribution of the brick samples from dolon' village, Kazakhstan / V.F. Stepanenko, E.K. Iaskova, T.V. Kolizshenkov, I.G. Kryukova, M. Hoshi, M. Yamamoto, A. Sakaguchi, J. Takada, H. Sato, K.N. Apsalikov, B.I. Gusev, H. Jungner // Journal of Radiation Research. - 2006. - V. 47. №. Suppl_A. - P. 15-21.

21. Reconstruction of local fallout composition and gamma-ray exposure in a village contaminated by the first USSR nuclear test in the Semipalatinsk nuclear test site in Kazakhstan / M. Yamamoto, K. Kawai, A. Sakaguchi, M. Hoshi, N. Chaizhunusova, K. Apsalikov // Radiation and Environmental Biophysics. - 2010. № 4. - P. 673-684.

22. Twinning in the offspring of parents with chronic radiation exposure from nuclear testing in Kazakhstan / N.Y. Mudie, A.J. Swerdlow, M.J. Schoemake, B.I. Gusev, L.M. Pivina, S. Chsherbakova, A. Mansarina, Y. Jakovlev, K.N. Apsalikov, S. Bauer // Radiation Research. - 2010. - № 6. - P. 829-836.

23. Закон Республики Казахстан от 18 декабря 1992 года № 1787-XII «0 социальной защите граждан, пострадавших вследствие ядерных испытаний на Семипалатинском испытательном ядерном полигоне URL: http://online.zakon.kz/ (дата обращения 03.03.2019).

24. Боев В.В., Перминова Т.С., Барановская Н.В. Распределение микро- и макроэлементов в почвах Томской области // Биогеохимия химических элементов и соединений в природных средах: материалы II Международной школы-семинара для молодых исследователей, посвященной памяти профессора В.Б. Ильина. - Тюмень: Изд-во Тюменского государственного университета, 2016. - С. 197-200.

25. Ярошевский А.А. Кларки геосфер. Справочник по геохимическим поискам полезных ископаемых. - М.: Недра, 1990. C. $7-14$.

26. Михальчук А.А., Язиков Е.Г. Многомерный статистический анализ эколого-геохимических измерений. Ч. І. Математические основы. - Томск: Изд-во ТПУ, 2014. - 103 с.

27. Геохимическая характеристика солевых отложений питьевых вод Байкальского региона / Б.Р. Соктоев, Л.П. Рихванов, Т.Т. Тайсаев, Н.В. Барановская // Известия Томского политехнического университета. - 2014. - Т. 324. - № 1. C. $209-223$.

28. Iyengar G.V., Kollmer W.E., Bowen H.J.M. The elemental composition of human tissues and body fluids. - Weinheim; New York: Verlag Chemie, 1978. - $7 \mathrm{p}$.

29. Элементный состав волос детского населения города Павлодар / Н.П. Корогод, Б.Х. Шайморданова, Г.Е. Асылбекова, Н.В. Барановская // Проблемы биогеохимии и геохимической экологии. - 2008. - Т. 8. - № 4. - С. 99-109.

30. Bowen N.J.M. Trace elements in biochemistry. - London; New York: Academic Press, 1966. - 241 p.

31. Глазовская М.А. Геохимия природных и техногенных ландшафтов СССР. - М.: Высш. шк., 1988. - 327 с.

Поступила: 02.04.2019 2.

\section{Информация об авторах}

Джалбаев M.T., аспирант отделения геологии Инженерной школы природных ресурсов Национального исследовательского Томского политехнического университета.

Барановская H.B., доктор биологических наук, профессор отделения геологии Инженерной школы природных ресурсов Национального исследовательского Томского политехнического университета.

Липихина A.B., кандидат биологических наук, профессор Российской Академии естествознания, ведущий научный сотрудник Научно-исследовательского института радиационной медицины и экологии некоммерческого акционерного общества «Медицинский университет Семей» . 
Боев В.В., аспирант отделения геологии Инженерной школы природных ресурсов Национального исследовательского Томского политехнического университета.

Paйылкулова M.K., стажер-исследователь Научно-исследовательского института радиационной медицины и экологии некоммерческого акционерного общества «Медицинский университет Семей» .

Ancаликова 3.C., докторант кафедры технологии пищевых продуктов и изделий легкой промышленности Государственного Университета им. Шакарима г. Семей.

Судыко А.Ф., инженер отделения геологии Инженерной школы природных ресурсов Национального исследовательского Томского политехнического университета. 


\title{
INDICATORS OF NUCLEAR TECHNOGENESIS ON THE EXAMPLE OF THE TERRITORIES ADJACENT TO THE FORMER SEMIPALATINSK TEST SITE
}

\author{
Merey T. Jambayev',
}

merei-semei@mail.ru

Natalya V. Baranovskaya',

natalya.baranovs@mail.ru

Aleksandra V. Lipikhina², a.v.lipikhina@mail.ru

Vladislav V. Boev', v.-3@mail.ru

Zukhra S. Apsalikova ${ }^{3}$ zingatinovazs@mail.ru

\section{Madina K. Raiymkulova²,} madina_rk@bk.ru

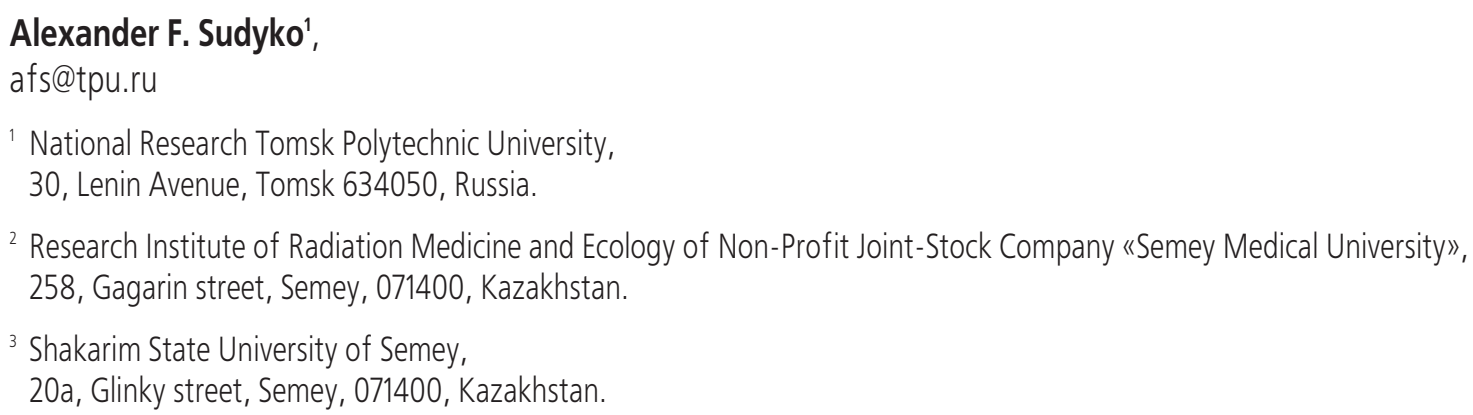

The relevance of the research is determined by the need to identify the indicator properties of chemical composition of the natural environment components, local and regional characteristics of their composition, taking into account natural and anthropogenic factors of influence in order to conduct environmental assessment and areas subdivision effected by nuclear technogenesis. Environmental zoning of the study areas was carried out only taking into account the dose loads of the population obtained as a result of the activities of the former Semipalatinsk test site. In this regard, it is necessary to study the natural geochemical specifics, which would allow a more accurate approach to the issue of environmental assessment of the studied areas, taking into account the complex impact of natural and man-made factors

The main aim of the research is the complex study of the elemental composition of the environment components in the territory adjacent to the former Semipalatinsk Test Site

Object of the research is the components of the environment (soil, salt deposits of drinking water, plant), food, biological objects.

Methods. Complex of environmental components was sampled in residential courtyards. The main criterion in selection of the investigated residential yards was the fact that the respondents lived there for at least 10 years. After appropriate preparation, the samples of the selected components were studied on instrumental neutron activation analysis

The paper introduces the results of a comprehensive study of elemental compositions of the environment components (soil, salt deposits of drinking water, biological objects, food products) that are in contact with them in the zone of influence of the former Semipalatinsk Test Site. Elements-indicators of the nuclear technogenesis effects were identified in the studied environment samples as a regional specificity of the chemical composition of the studied territory shown in $U$ and Zn accumulation.

Key words:

Accumulation of chemical elements, geochemical accumulation series, concentration coefficients, components of environment, indicators of nuclear technogenesis.

\section{REFERENCES}

1. Serzhanova Z.B., Aidarkhanova A.K., Lukashenko S.N., Lyakhova $0 . N$., Timonova L.V., Raimkanova A.M. Researching of tritium speciation in soils of «Balapan» site. Journal of environmental radioactivity, 2018, Vol. 192, pp. 621-627.

2. Kabdyrakova A.M., Lukashenko S.N., Mendubaev A.T., Kunduzbayeva A.Y., Panitskiy A.V., Larionova N.V. Distribution of ar- tificial radionuclides in particle-size fractions of soil on fallout plumes of nuclear explosions. Journal of environmental radioactivity, 2018, vol. pp. 45-53.

3. Larionova N.V., Lukashenko S.N., Kabdyrakova A.M., Kunduzbayeva A.Y., Panitskiy A.V., Ivanova A.R. Transfer of radionuclides to plants of natural ecosystems at the semipalatinsk test site. Journal of environmental radioactivity, 2018, vol. 186, pp. 63-70. 
4. Aidarkhanova A.K., Lukashenko S.N., Larionova N.V., Polevik V.V. Radionuclide transport in the «sediments-water-plants» system of the water bodies at the Semipalatinsk test site. Journal of environmental radioactivity, 2018, vol. 184, pp. 122-126.

5. Toropov A.S. Fractionation of technogenic radionuclides species in water bodies of Semipalatinsk test site. Bulletin of the Tomsk Polytechnic University, Geo Assets Engineering, 2018. Vol. 329, no 6, pp. 74-84. In Rus.

6. Yao J., Tian D., Lu Z., Sun L., Wen L. Triggered seismicity after north Korea's 3 September 2017 nuclear test. Seismol Res Lett, 2018, vol. 89, no. 6, pp. 2085-2093.

7. Romanenko V.V., Aiunov D.E., Duchkov A.D., Kazantsev S.A. Teplovye osobennosti v rayone «boevoy" skvazhiny 104 semipalatinskogo ispytatelnogo poligona [Thermal features in the area of "combat" bore 104 of the Semipalatinsk test site]. Interexpo GEO-Siberia, 2017, vol. 2, no. 4, pp. 123-128.

8. Duyssembaev S., Serikova A., Suleimenov S., Ikimbayeva N., Zhexenayeva A., Akhemtzhanova A., Atambayeva Z. Radioecological monitoring of adjacent territories to the former Semipalatinsk nuclear test site, east Kazakhstan. International Journal of Engineering and Technology, 2018, vol. 7, pp. 323-328. In Rus.

9. Dyusembaev S.T., Serikova A.T., Iminova D.E. Content of americium-241 and cesium-137 in environmental samples and animal products. Young scientist, 2017, no. 6.1, pp. 11-17. In Rus.

10. Kakimov A., Yessimbekov Z., Kakimova Z., Bepeyeva A., Stuart M. Cs-137 in milk, vegetation, soil, and water near the former soviet Union's Semipalatinsk Nuclear Test Site, Environmental Science and Pollution Research, 2016, Vol. 23, no. 5, pp. 493-497.

11. Kozhanov T.E., Lukashenko S.N. Soderzhanie radionuklidov ${ }^{137} \mathrm{Cs},{ }^{90} \mathrm{Sr},{ }^{239+240} \mathrm{Pu} \mathrm{i}{ }^{241} \mathrm{Am}$ v produktsii rastenievodstva na territoriyakh, prilegayushchikh k Semipalatinskomu ispytatelnomu poligonu [The content of radionuclides ${ }^{137} \mathrm{Cs},{ }^{90} \mathrm{Sr}$, ${ }^{239+240} \mathrm{Pu}$ and ${ }^{241} \mathrm{Am}$ in production of crops in the areas adjacent to the Semipalatinsk test site]. Radiation biology. Radioecology, 2017, no. 2 , pp. 220-225.

12. Brown J.W.N., Brockman J.D., Robertson J.D. Measurement of ${ }^{239} \mathrm{Pu}$ in keratinous materials: A potential non-invasive bioassay for monitoring human exposure. Applied Radiation and Isotopes, 2017, vol. 128. pp. 132-135.

13. Dzhambaev M.T., Zhakupova Sh.B., Brayt Yu.Yu. Uran v pitevoy vode i krovi cheloveka v zone vliyaniya Semipalatinskogo yadernogo poligona [Uranium in drinking water and human blood in the zone of influence of Semipalatinsk nuclear test site]. Proble my geologii i osvoeniya nedr. Trudy XX Mezhdunarodnogo simpoziuma imeni akademika M.A. Usova studentov i molodykh uchenykh, posvyashhennogo 120-letiyu so dnya osnovaniya Tomskogo politekhnicheskogo universiteta [Problems of Geology and exploitation of mineral resources. Proc. of the XX International Symposium named after academician M.A. Usov for students and young scientists, dedicated to the $120^{\text {th }}$ anniversary of the founding of Tomsk Polytechnic University]. Tomsk, Tomsk Polytechnic University Publ. house, 2016. pp. 122-124.

14. Apsalikov K.N., Lipikhina A., Grosche B., Belikhina T., Ostroumova E., Shinkarev S., Stepanenko V., Muldagaliev T., Yoshinaga S., Zhunussova T., Hoshi M., Katayama H., Lackland D.T., Simon S.L., Kesminiene A. The state scientific automated medical registry, Kazakhstan: An important resource for low-dose radiation health research. Radiat Environ Biophys, 2019, vol. 58, no. 1, pp. 1-11.

15. Kolyado I.B., Plugin S.V., Tribunsky S.I. Posledstviya vliyaniya radiatsionnogo vozdeystviya na territoriyu i naselenie Altayskogo kraya [Aftereffects of radiation exposure impact on the territory and the population of the Altai krai]. Gig Sanit, 2018, vol. 97, no. 7, pp. 609-617.

16. Baranovskaya N.V., Rikhvanov L.P., Ignatova T.N. Narkovich D.V., Denisova 0.A. Ocherki geokhimii cheloveka [Essays on
Geochemistry of the human]. Tomsk, Deltaplan Publ., 2015. $377 \mathrm{p}$.

17. Muldagaliev T. Apsalikov K., Belihina T. Scientific foundations of screening organization of the state of health of Kazakhstanean population subjected to radiation, analyses of the results, development prenozological preventive measures and rehabilitation. $17^{\text {th }}$ Hiroshima International Symposium. Japan, 2012, 43 p.

18. Lipikhina A.V. Radioekologicheskaya obstanovka i otsenka dozovykh nagruzok ot dolgovremennogo vozdeystviya radionuklidov $v$ rayone Semipalatinskogo ispytatelnogo yadernogo poligona: na primere Abayskogo rayona. Avtoreferat Dis. Kand. nauk [Radioecological situation and assessment of dose loads from long-term exposure to radionuclides in the area of the Semipalatinsk nuclear test site: on the example of Abay district. Cand. Diss. Abstract]. Tomsk, 2005. $163 \mathrm{p}$.

19. Akleev A.V. Reaktsiya tkaney na khronicheskoe vozdeystvie ioniziruyushchego izlucheniya [Tissue reaction to chronic exposure to ionizing radiation]. Radiation biology. Radioecology, 2009, no. 1 , pp. 5-20.

20. Stepanenko V.F., Iaskova E.K., Kolizshenkov T.V., Kryukova I.G., Hoshi M., Yamamoto M., Sakaguchi A., Takada J., Sato H., Apsalikov K.N., Gusev B.I., Jungner H. International intercomparison of retrospective luminescence dosimetry method: sampling and distribution of the brick samples from dolon' village, Kazakhstan. Journal of Radiation Research, 2006, vol. 47, no. Suppl_A, pp. 15-21.

21. Yamamoto M., Kawai K., Sakaguchi A., Hoshi M., Chaizhunusova N., Apsalikov K. Reconstruction of local fallout composition and gamma-ray exposure in a village contaminated by the first USSR nuclear test in the Semipalatinsk nuclear test site in Kazakhstan. Radiation and Environmental Biophysics, 2010, no. 4. pp. 673-684.

22. Mudie N.Y., Swerdlow A.J., Schoemake M.J., Gusev B.I, Pivina L.M., Chsherbakova S., Mansarina A., Jakovlev Y., Apsalikov K.N., Bauer S. Twinning in the offspring of parents with chronic radiation exposure from nuclear testing in Kazakhstan. Radiation Research, 2010, no. 6, pp. 829-836.

23. Zakon Respubliki Kazakhstan ot 18 dekabrya 1992 goda № 1787 . XII «O sotsialnoy zashchite grazhdan, postradaushikh vsledstvie yadernykh ispytaniy na Semipalatinskom ispytatelnom yadernom poligone» [Law of the Republic of Kazakhstan No. 1787-XII of 18 December 1992 on the social protection of citizens affected by nuclear tests at the Semipalatinsk nuclear test site]. Available at: http://online.zakon.kz/ (accessed 03 March 2009).

24. Boev V.V., Perminova T.S., Baranovskaya N.V. Raspredelenie mikro- i makroelementov v pochvakh Tomskoy oblasti [In distribution of micro-and macroelements in soils of the Tomsk region]. Biogeokhimiya khimicheskikh elementov $i$ soedineniy $v$ prirodnykh sredakh. Materialy II Mezhdunarodnoy shkoly-seminara dlya molodykh issledovateley, posvyashhennoy pamyati professora V.B. Ilina [Biogeochemistry of chemical elements and compounds in natural environments. Materials of the II International school-seminar for young researchers dedicated to the memory of Professor V. B. Ilyin]. Tyumen, Tyumen state University Publ. house, 2016. pp. 197-200.

25. Yaroshevsky A.A. Klarki geosfer. Spravochnik po geokhimicheskim poiskam poleznykh iskopaemykh [Clark of Geosphere. Handbook of geochemical prospecting for minerals]. Moscow, Nedra Publ., 1990. pp. 7-14.

26. Mikhalchuk A.A., Yazikov E.G. Mnogomerny statisticheskiy analiz ekologo-geokhimicheskikh izmereniy. Ch. I. Matematicheskie osnovy [Multivariate statistical analysis of ecological and geochemical measurements. P. I. Mathematical foundations]. Tomsk, TPU Publ. house, 2014. $103 \mathrm{p}$.

27. Soktoev B.R., Rikhvanov L.P., Taysaev T.T., Baranovskaya N.V. Geochemical characteristics of salt deposits of drinking waters of the Baikal region. Bulletin of the Tomsk Polytechnic University, 2014, vol. 324, no. 1, pp. 209-223. In Rus. 
28. Iyengar G.V. Kollmer W.E., Bowen H.J.M. The elemental composition of human tissues and body fluids. Weinheim; New York, Verlag Chemie, 1978. 7 p.

29. Korogod N.P., Shaymordanova B.Kh., Asylbekova G.E., Baranovskaya N.V. The elemental composition of the children's hair of the city of Pavlodar. Problems of biogeochemistry and geochemical ecology, 2008, vol. 8, no. 4, pp. 99-109. In Rus.
30. Bowen N.J.M. Trace elements in biochemistry. London-New York, Academic Press, 1966. 241 p.

31. Glazovskaya M.A. Geokhimiya prirodnykh i texnogennykh landshaftov SSSR [Geochemistry of natural and man-made landscapes of the USSR]. Moscow, Vysshaya shkola Publ., 1988. 327 p.

Received: 02.04.2019

\section{Information about the authors}

Merey T. Jambayev, postgraduate student, National Research Tomsk Polytechnic University.

Natalia V. Baranovskaya, Dr. Sc., professor, National Research Tomsk Polytechnic University.

Aleksandra V. Lipikhina, Cand. Sc., professor, Research Institute of Radiation Medicine and Ecology of Non-Profit Joint-Stock Company «Semey Medical University».

Vladislav V. Boev, postgraduate student, National Research Tomsk Polytechnic University.

Madina K. Raiymkulova, research intern, Research Institute of Radiation Medicine and Ecology of Non-Profit Joint-Stock Company «Semey Medical University».

Zukhra S. Apsalikova, doctoral student, Shakarim State University of Semey.

Alexander F. Sudyko, engineer, National Research Tomsk Polytechnic University. 
Компьютерная верстка О.Ю. Аршинова Корректура и перевод на английский язык С.В. Жаркова Дизайн обложки Т.В. Буланова

Фотографии на обложке взяты из личного архива Валерия Касаткина

Руководство для авторов и образец оформления статьи: izvestiya.tpu.ru

Подписано к печати 29.04.2019. Формат 60х84/8. Бумага «Снегурочка».

Печать XEROX. Усл. печ. л. 26,75. Уч.-изд. л. 24,20. Заказ 106-19. Тираж 500 экз.

\section{Издательство}

ТОМСКИЙ ПОЛИТЕХНИЧЕСКИЙ УНИВЕРСИТЕТ 